ISSN : 2623-2553 (Online)

ISSN : 2549-0532 (Cetak)

\title{
HUBUNGAN PREEKLAMPSIA BERAT DENGAN KOMPLIKASI PADA JANIN DI RSUD ABDUL WAHAB SJAHRANIE SAMARINDA TAHUN 2017-2018
}

\author{
Mita Maulida Rifqiya Faiza ${ }^{1}$, Novia Fransiska $\mathrm{Ngo}^{2}$, Ika Fikriah ${ }^{3}$ \\ ${ }^{I}$ Program Studi Pendidikan Dokter, Fakultas Kedokteran Universitas Mulawarman \\ ${ }^{2}$ Laboratorium Obstetri dan Ginekologi, Fakultas Kedokteran, Universitas \\ Mulawarmanan \\ ${ }^{3}$ Laboratorium Ilmu Farmakologi, Fakultas Kedokteran, Universitas Mulawarman \\ Email:mitamaulida97@gmail.com,novia_fn2002@yahoo.com,ika_fikriah@yahoo.com \\ $\begin{array}{ll}\text { Dikirim } & : 5 \text { September } 2019 \\ \text { Diterima } & : 20 \text { September } 2019 \\ \text { Dipublikasi } & : 28 \text { September } 2019\end{array}$
}

\begin{abstract}
Preeclampsia defined as new onset of hypertension and proteinuria after 20 weeks of gestation. Preeclampsia is one of the three main causes of maternal mortality with an incidence of 128,273 each year or around 5.3\% in Indonesia. Preeclampsia is classified as preeclampsia without severe features and severe preeclampsia. Severe preeclampsia can be a problem, both in the mother and the fetus due to vascular vasospasm. If uteroplacental blood flow to the fetus is limited, the fetus can be born under low birth weight (LBW), preterm birth, intra uterine fetal death, and low Apgar score. The aim of this research is to determine the correlation of severe preeclampsia with fetal complication, that is intra uterine fetal death (IUFD), preterm labor, neonatal asphyxia, and low birth weight (LBW). The design of this research is case control study with 46 sample for both case and control groups. The data analysis used chi-square for $2 \times 2$ table and likelihood ratio for $2 \times 3$ table. The results of this this research is showed that there was correlation between severe preeclampsia with preterm labor $(p=0,000)$ and severe preeclampsia with low birth weight $(p=0,000)$, there was no correlation between severe preeclampsia with IUFD $(p=0,822)$ and severe preeclampsia with neonatal asphyxia $(p=0,060)$.
\end{abstract}

Keywords : Severe preeclampsia, intra uterine fetal death (IUFD), neonatal asphyxia, low birth weight ( $L B W)$ 
Jurnal Kebidanan Mutiara Mahakam, Vol 7 , No 2, 2019, Hal 74-84

\section{PENDAHULUAN}

World Health Organization (2018) memperkirakan setiap hari terdapat 830 wanita meninggal akibat komplikasi terkait kehamilan atau persalinan di seluruh dunia, dimana 99\% diantaranya terjadi di negara berkembang. Diperkirakan pada tahun 2015, sekitar 303.000 wanita meninggal selama kehamilan dan persalinan. Rasio kematian ibu di negara berkembang di tahun 2015 berkisar 239 per 100.000 kelahiran hidup, sementara di Negara maju angka ini jauh lebih rendah dibandingkan negara berkembang, yaitu berkisar 12 per 100.000 kelahiran hidup.

Tiga penyebab utama kematian ibu adalah perdarahan (30\%), hipertensi dalam kehamilan (25\%), dan infeksi (12\%) (Perkumpulan Obstetri dan Ginekologi Indonesia , 2016). Berdasarkan Report of the National High Blood Pressure Education Program Working Group on High Blood Pressure in Pregnancy terdapat 4 kategori hipertensi dalam kehamilan, yakni hipertensi kronik, preeklampsia-eklampsia, hipertensi kronik dengan superimposed preeklampsia, dan hipertensi gestasional (Prawirohardjo, 2014).

Preeklampsia merupakan hipertensi yang timbul setelah 20 minggu kehamilan disertai dengan proteinuria (Prawirohardjo, 2014). Preeklampsia dikelompokkan menjadi preeklampsia tanpa gejala berat dan preeklampsia berat, dimana preeklampsia tanpa gejala berat ditandai dengan tekanan darah $\geq 140 / 90 \mathrm{mmHg}$ dan proteinuria $\geq 300 \mathrm{mg} / 24$ jam. Sementara preeklampsia berat ditandai dengan tekanan darah $\geq 160 / 110 \mathrm{mmHg}$ disertai proteinuria >5g/24 jam (POGI, 2016).

Prevalensi preeklampsia di negara maju adalah 1,3\% - 6\%, sedangkan di negara berkembang adalah 1,8\% - 16,7\% (POGI, 2016). Setiap tahunnya, 10 juta wanita dapat mengalami preeklampsia di seluruh dunia. Dimana sekitar 76.000 wanita hamil dapat meninggal setiap tahun akibat preeklampsia dan gangguan hipertensi terkait kehamilan. Dan jumlah bayi yang meninggal akibat gangguan ini diperkirakan 500.000 per tahun. Di negara berkembang, insidensi preeklampsia tujuh kali lebih tinggi dari pada di negara maju, dimana 10-25\% dari kasus preeklampsia ini akan menyebabkan kematian pada ibu (Preeclampsia Foundation, 2013).

Insiden preeklampsia di Indonesia sendiri adalah 128.273/tahun atau sekitar 5,3\% (POGI, 2016). Berdasarkan penelitian terdahulu yang dilakukan oleh Wibisono (2010) di RSUD Abdul Wahab Sjahranie Kalimantan Timur terdapat 484 kasus (9.8\%) preeklampsia berat dari 4955 kelahiran selama periode 2008 hingga 2009. Dimana dalam kurun waktu 2 tahun tersebut, terdapat peningkatan presentase penderita preeklampsia berat yaitu sebesar $9.3 \%$ pada tahun 2008 dan $10.20 \%$ pada tahun 2009 . 
Jurnal Kebidanan Mutiara Mahakam, Vol 7 , No 2, 2019, Hal 74-84

Preeklampsia berat dapat menjadi masalah, baik pada ibu ataupun pada janin karena adanya vasospasme pembuluh darah, sehingga aliran darah uteroplasenta ke janin terbatas, akibatnya janin dapat terlahir dalam keadaan berat bayi lahir rendah (BBLR), kelahiran prematur, intra uterine fetal death, serta Apgar score yang rendah (Ngwenya, 2017).

Sehubungan dengan angka kejadian preeklampsia yang cukup tinggi di Indonesia serta dampaknya pada janin yang dapat ditimbulkan, maka peneliti tertarik untuk melakukan penelitian untuk mengetahui hubungan antara preeklampsia berat dengan komplikasi pada janin.

\section{METODE PENELITIAN}

Desain penelitian ini bersifat observasional analitik dengan pendekatan case control secara purposive sampling menggunakan data sekunder pasien. Sampel kasus pada penelitian ini adalah ibu hamil yang didiagnosis dengan preeklampsia berat yang melahirkan di RSUD Abdul Wahab Sjahranie selama periode 1 Januari 2017 - 31 Desember 2018, sementara untuk sampel kontrol adalah ibu hamil yang tidak didiagnosis dengan preeklampsia berat yang melahirkan di RSUD Abdul Wahab Sjahranie selama periode 1 Januari 2017 - 31 Desember 2018. Variabel bebas ialah preeklampsia berat, sementara variabel terikat ialah IUFD, persalinan prematur, asfiksia neonatorum, dan BBLR.

Definisi operasional preeklampsia berat adalah Ibu hamil dengan tekanan darah $\geq$ $160 / 110 \mathrm{mmHg}$ disertai proteinuria $>5 \mathrm{~g} / 24$ jam atau dengan tes dipstick urin $\geq+2$ atau adanya tekanan darah $<160 / 110 \mathrm{mmHg}$ disertai salah satu gejala berikut, yakni sakit kepala, penglihatan kabur, nyeri hipokondrial kanan, muntah, papil edema, dan sindroma HELLP. IUFD adalah Janin yang mati dalam rahim dengan berat badan $\geq 500$ gram atau kematian janin pada $\geq$ kehamilan 20 minggu. Persalinan prematur adalah Persalinan yang berlangsung pada umur kehamilan 20 minggu hingga sebelum 37 minggu dihitung dari hari pertama haid terakhir. Asfiksia neonatorum adalah Kegagalan nafas secara spontan dan teratur segera setelah lahir. Serta BBLR adalah Bayi yang dilahirkan dengan berat badan <10 persentil menurut grafik Lubchenco. Analisis data dalam penelitian ini menggunakan uji statistik chi-square untuk tabel $2 \times 2$ dan likelihood ratio untuk tabel $2 \times 3$. 
Jurnal Kebidanan Mutiara Mahakam, Vol 7 , No 2, 2019, Hal 74-84

\section{HASIL DAN PEMBAHASAN}

Penelitian ini dilakukan di Instalasi Rekam Medik RSUD Abdul Wahab Sjahranie Samarinda denganjumlah sampel sebanyak 46 untuk kelompok kasus dan 46 untuk kelompok kontrol.

Tabel 1. Karakteristik ibu dengan preeklampsia berat yang melahirkan di RSUD Abdul Wahab Sjahranie Samarinda

\begin{tabular}{|c|c|c|c|c|}
\hline & \multicolumn{2}{|c|}{ Kasus } & \multicolumn{2}{|c|}{ Kontrol } \\
\hline & $\mathrm{n}$ & $(\%)$ & $\mathrm{n}$ & $(\%)$ \\
\hline \multicolumn{5}{|l|}{ Usia } \\
\hline - $<20$ tahun & 2 & 4,3 & 2 & 4,3 \\
\hline - 20-35 tahun & 24 & 52,2 & 24 & 52,2 \\
\hline - $\quad>35$ tahun & 20 & 43,5 & 20 & 43,5 \\
\hline \multicolumn{5}{|l|}{ Paritas } \\
\hline - Nullipara & 11 & 23,9 & 11 & 23,9 \\
\hline - $\quad$ Primipara & 11 & 23,9 & 11 & 23,9 \\
\hline - Multipara & 24 & 52,2 & 24 & 52,2 \\
\hline \multicolumn{5}{|l|}{ Pendidikan } \\
\hline - $\mathrm{SD}$ & 6 & 13 & 7 & 15,2 \\
\hline - SMP & 6 & 13 & 15 & 32,6 \\
\hline - SMA & 20 & 43,5 & 18 & 39,1 \\
\hline - D3 & 2 & 4,3 & - & - \\
\hline - $\mathrm{S} 1$ & 12 & 26,1 & 6 & 13 \\
\hline \multicolumn{5}{|l|}{ Cara Persalinan } \\
\hline - Sectio caesaria & 33 & 71,7 & 3 & 6,5 \\
\hline - Spontan & 13 & 28,3 & 43 & 93,5 \\
\hline \multicolumn{5}{|c|}{ Kondisi Penyakit Tambahan pada Sampel } \\
\hline - Perdarahan antepartum & 1 & 2 & - & - \\
\hline - Hipotonia uteri & 1 & 2 & - & - \\
\hline - Kelainan kongenital & 1 & 2 & 1 & 2 \\
\hline - Solusio plasenta & 2 & 4 & 1 & 2 \\
\hline - Impending eklampsia & 4 & 7 & - & - \\
\hline - Oligohiramnion & 5 & 9 & 4 & 8 \\
\hline - Sindroma HELLP & 12 & 22 & - & - \\
\hline - Bekas sectio caesaria & 12 & 22 & 4 & 8 \\
\hline - Ruptur perineum & - & - & 4 & 8 \\
\hline - Retensio plasenta & - & - & 1 & 2 \\
\hline - Letak sungsang & - & - & 6 & 13 \\
\hline - Tanpa komplikasi & 17 & 31 & 27 & 56 \\
\hline \multicolumn{5}{|l|}{ IUFD } \\
\hline - $Y \mathrm{Y}$ & 15 & 32,6 & 14 & 30,4 \\
\hline - Tidak & 31 & 67,4 & 32 & 69,6 \\
\hline \multicolumn{5}{|l|}{ Persalinan premature } \\
\hline - $Y a$ & 23 & 50 & 4 & 8,7 \\
\hline - Tidak & 23 & 50 & 42 & 91,3 \\
\hline \multicolumn{5}{|l|}{ Asfiksia neonatorum } \\
\hline - Ringan-sedang & 3 & 6,5 & 1 & 2,2 \\
\hline
\end{tabular}


Jurnal Kebidanan Mutiara Mahakam, Vol 7 , No 2, 2019, Hal 74-84

\begin{tabular}{|c|c|c|c|c|c|}
\hline$\bullet$ & $\begin{array}{l}\text { Berat } \\
\text { Tidak asfiksia }\end{array}$ & $\begin{array}{c}6 \\
37\end{array}$ & $\begin{array}{c}13 \\
80,5\end{array}$ & $\begin{array}{c}1 \\
44\end{array}$ & $\begin{array}{c}2,2 \\
95,7\end{array}$ \\
\hline BBLF & & & & & \\
\hline • & $\mathrm{Ya}$ & 14 & 30,4 & 1 & 2,2 \\
\hline - & Tidak & 32 & 69,6 & 45 & 97,8 \\
\hline
\end{tabular}

Tabel 2 Tabulasi silang preeklampsia berat dengan Intra Uterine Fetal Death (IUFD)

\begin{tabular}{|c|c|c|c|c|c|c|c|c|c|}
\hline & & \multicolumn{4}{|c|}{ IUFD } & \multirow{2}{*}{\multicolumn{2}{|c|}{ Total }} & \multirow{3}{*}{$\begin{array}{c}\mathrm{p}- \\
\text { value }\end{array}$} & \multirow{3}{*}{ OR } \\
\hline & & \multicolumn{2}{|c|}{$\mathrm{Ya}$} & \multicolumn{2}{|c|}{ Tidak } & & & & \\
\hline & & $\mathrm{n}$ & $(\%)$ & $\mathrm{n}$ & $(\%)$ & $\mathrm{n}$ & $(\%)$ & & \\
\hline \multirow{2}{*}{$\begin{array}{l}\text { Preeklampsia } \\
\text { Berat }\end{array}$} & $\mathrm{Ya}$ & 15 & 32,6 & 31 & 67,4 & 46 & 100 & \multirow{2}{*}{0,822} & \multirow{2}{*}{1,106} \\
\hline & Tic & 14 & 30.4 & 32 & 69.6 & 46 & 100 & & \\
\hline
\end{tabular}

Tabel 2. hasil analisis hubungan antara preeklampsia berat dengan intra uterine fetal death (IUFD) menunjukkan bahwa dari 46 ibu yang mengalami preeklampsia berat terdapat 15 ibu yang mengalami komplikasi janin berupa IUFD (32,6\%). Sementara pada kelompok yang tidak mengalami preeklampsia berat terdapat 14 ibu yang mengalami komplikasi janin berupa IUFD (30,4\%). Hasil analisis statistik chi-square diperoleh $p$ value $=0,822$, hal ini membuktikan bahwa tidak terdapat hubungan yang bermakna antara preeklampsia berat dengan intra uterine fetal death (IUFD).

Hasil penelitian ini sejalan dengan penelitian yang dilakukan oleh Gumay, Wijayanegara, \& Zulmansyah (2015) dan Kirana (2014) yang menunjukan bahwa ibu dengan preeklampsia berat tidak memiliki hubungan dengan intra uterine fetal death (IUFD) dengan nilai $\mathrm{p}>0,05$. Namun, Hasil penelitian ini berbeda dengan penelitian yang dilakukan oleh PWP (2016) yang menunjukan terdapat hubungan yang bermakna antara preeklampsia berat dengan intra uterine fetal death (IUFD) dengan risiko sebesar 3,396 .

Pada penelitian ini tidak ditemukan hubungan antara preeklampsia berat dengan intra uterine fetal death (IUFD). Hal ini mungkin disebabkan oleh jumlah sampel penelitian yang kurang sehingga diperlukan jumlah sampel yang lebih besar agar diperoleh proporsi yang seimbang. Selain itu terhadap faktor-faktor lain yang dapat mempengaruhi terjadinya intra uterine fetal death (IUFD) namun tidak diteliti seperti diabetes mellitus, solusio plasenta, letak sunsang, dan kelainan kongenital. 
Jurnal Kebidanan Mutiara Mahakam, Vol 7 , No 2, 2019, Hal 74-84

Tabel 3. Tabulasi silang preeklampsia berat dengan persalinan prematur Persalinan prematur

\begin{tabular}{|c|c|c|c|c|c|c|c|c|c|}
\hline & & \multicolumn{4}{|c|}{ Persalinan prematur } & \multirow{2}{*}{\multicolumn{2}{|c|}{ Total }} & \multirow{3}{*}{$\begin{array}{c}\mathrm{p}- \\
\text { value }\end{array}$} & \multirow{3}{*}{ OR } \\
\hline & & \multicolumn{2}{|c|}{ Ya } & \multicolumn{2}{|c|}{ Tidak } & & & & \\
\hline & & $\mathrm{n}$ & $(\%)$ & $\mathrm{n}$ & $(\%)$ & $\mathrm{n}$ & $(\%)$ & & \\
\hline \multirow{2}{*}{$\begin{array}{l}\text { Preeklampsia } \\
\text { Berat }\end{array}$} & $\mathrm{Ya}$ & 23 & 50 & 23 & 50 & 46 & 100 & \multirow{2}{*}{0,000} & \multirow{2}{*}{10,500} \\
\hline & Tidak & 4 & 8,7 & 42 & 91,3 & 46 & 100 & & \\
\hline
\end{tabular}

Tabel 3. hasil analisis hubungan antara preeklampsia berat dengan persalinan prematur menunjukan bahwa dari 46 ibu yang mengalami preeklampsia berat terdapat 23 ibu yang melakukan persalinan prematur (50\%). Sementara pada kelompok yang tidak mengalami preeklampsia berat terdapat 4 ibu yang melakukan persalinan prematur $(8,7 \%)$. Hasil analisis chi-square diperoleh $p$ value $=0,000$ dan nilai OR sebesar 10,5. Hal ini menunjukan bahwa terdapat hubungan bermakna antara preeklampsia berat dengan persalinan prematur, dan ibu dengan preeklampsia berat memiliki risiko 10,5 kali untuk mengalami persalinan prematur dibanding ibu tanpa preeklampsia berat.

Hasil penelitian ini sesuai dengan penelitian yang dilakukan oleh Gumay, Wijayanegara, \& Zulmansyah (2015) dan Saputra (2017) yang menunjukan bahwa ibu dengan preeklampsia berat memiliki risiko 3,303 kali dan 4,5 untuk melakukan persalinan prematur dibandingkan ibu tanpa preeklampsia berat.

Secara teori, preeklampsia berat dapat menyebabkan kelahiran prematur karena adanya spasme pembuluh darah yang akan menurunkan aliran darah ke plasenta sehingga terjadi gangguan fungsi plasenta. Jika spasme berlangsung lama akan mengganggu pertumbuhan janin. Jika terjadi peningkatan tonus dan kepekaan uterus terhadap rangsangan dapat menyebabkan partus prematurus (Mutianingsih, 2014).

Pada penelitian ini nilai OR yang diperoleh adalah 10,5 lebih tinggi dibandingkan penelitian yang dilakukan oleh Saputra (2017) dan Gumay, Wijayanegara, \& Zulmansyah (2015), hal ini mungkin disebabkan karena adanya penyulit preeklampsia berat lain yang dialami oleh ibu, seperti sindroma HELLP, impending eklampsia, riwayat sectio caesaria, dan oligohidramnion. Selain itu, penyakit penyerta yang sudah dialami oleh ibu sebelumnya juga dapat mempengaruhi kehamilan dan dapat meningkatkan kejadian persalinan prematur, terutama penyakit sistemik yang dapat mempengaruhi peredaran darah dan oksigenasi, seperti dislipidemia, edema paru, stroke non hemoragik, diabetes mellitus, dan gagal jantung kongstif.

Faktor usia ibu serta paritas yang berisiko juga dapat mempengaruhi terjadinya persalinan prematur pada ibu dengan preeklampsia berat. Usia ibu yang berisiko yakni 
Jurnal Kebidanan Mutiara Mahakam, Vol 7 , No 2, 2019, Hal 74-84

$<20$ tahun dan $>35$ tahun. Usia $<20$ tahun berisiko tinggi terhadap kehamilan dikarenakan pada usia tersebut organ reproduksi dan fungsi fisiologis belum optimal dan secara psikologis belum tercapainya emosi dan kejiwaan yang cukup dewasa sehingga akan berpengaruh terhadap janin yang dikandungnya (Oktaviani, 2017), sementara pada usia $>35$ tahun telah terjadi penurunan fungsi organ reproduksi yang akan mempengaruhi kesehatan baik ibu maupun janinnya, adanya kehamilan membuat ibu memerlukan ekstra energi untuk kehidupannya dan juga kehidupan janin yang sedang dikandungnya. Selain itu pada proses kelahiran diperlukan tenaga yang lebih besar dengan kelenturan dan elastisitas jalan lahir yang semakin berkurang (Rahmawati D. , 2013).

Resiko kesehatan ibu dan anak meningkat pada persalinan pertama, keempat dan seterusnya. Kehamilan dan persalinan pertama meningkatkan resiko kesehatan yang timbul karena ibu belum pernah mengalami kehamilan sebelumnya, selain itu jalan lahir baru akan dicoba dilalui janin. Sebaliknya jika terlalu sering melahirkan rahim akan menjadi semakin lemah karena jaringan parut uterus akibat kehamilan berulang. Jaringan parut ini menyebabkan tidak adekuatnya persediaan darah ke plasenta sehingga plasenta tidak mendapat aliran darah yang cukup untuk menyalurkan nutrisi ke janin akibatnya pertumbuhan janin terganggu. Hal tersebut akan meningkatkan resiko terjadinya persalinan preterm (Rahmawati D. , 2013).

Tabel 4. Tabulasi silang preeklampsia berat dengan asfiksia neonatorum

\begin{tabular}{|c|c|c|c|c|c|c|c|c|c|c|c|c|}
\hline \multicolumn{13}{|c|}{ Asfiksia Neonatorum } \\
\hline & & \multirow{2}{*}{\multicolumn{2}{|c|}{$\begin{array}{l}\text { Ringan- } \\
\text { sedang }\end{array}$}} & \multirow{2}{*}{\multicolumn{2}{|c|}{ Berat }} & \multirow{2}{*}{\multicolumn{2}{|c|}{$\begin{array}{c}\text { Tidak } \\
\text { asfiksia }\end{array}$}} & \multirow{2}{*}{\multicolumn{2}{|c|}{ Total }} & \multirow{3}{*}{$\begin{array}{l}\text { p- } \\
\text { val } \\
\text { ue }\end{array}$} & \multicolumn{2}{|c|}{ OR } \\
\hline & & & & & & & & & & & \multirow{2}{*}{$\begin{array}{l}\text { Ringan- } \\
\text { sedang }\end{array}$} & \multirow[t]{2}{*}{ Berat } \\
\hline & & $\mathrm{n}$ & $(\%)$ & $\mathrm{n}$ & $(\%)$ & $\mathrm{n}$ & $(\%)$ & $\mathrm{n}$ & $(\%)$ & & & \\
\hline \multirow[t]{2}{*}{ PEB } & $\mathrm{Ya}$ & 3 & 6,5 & 6 & 13 & 37 & 80,5 & 46 & 100 & 0,0 & \multirow{2}{*}{0,280} & \multirow{2}{*}{0,140} \\
\hline & Tidak & 1 & 2,2 & 1 & 2,2 & 44 & 95,7 & 46 & 100 & 60 & & \\
\hline
\end{tabular}


Tabel 4. hasil analisis hubungan antara preeklampsia berat dengan asfiksia neonatorum menunjukan bahwa dari 46 ibu yang mengalami preeklampsia berat terdapat 6 ibu yang mengalami komplikasi janin berupa asfiksia berat (13\%) dan 3 yang mengalami asfiksia ringan - sedang (6,5\%). Sementara pada kelompok yang tidak mengalami preeklampsia berat masing-masing terdapat $1 \mathrm{ibu}$ yang mengalami komplikasi janin berupa asfiksia berat dan asfiksia ringan - sedang (2,2\%). Hasil analisis chi-square diperoleh nilai $p$ value $=0,060$, hal ini menunjukkan bahwa tidak terdapat hubungan yang bermakna antara preeklampsia berat dengan asfiksia neonatorum.

Hasil penelitian ini sejalan dengan penelitian yang dilakukan oleh Heriyanti (2009) yang menunjukan bahwa preeklampsia berat tidak memiliki hubungan dengan komplikasi pada janin berupa asfiksia neonatorum dengan nilai $\mathrm{p}>0,05$. Namun, hasil penelitian ini berbeda dengan penelitian yang dilakukan oleh Johan \& Sunarsih (2013) dan Gumay, Wijayanegara, \& Zulmansyah (2015) yang menunjukan bahwa ibu dengan preeklampsia berat memiliki risiko 6,515 kali dan 2,483 kali untuk melahirkan bayi dengan asfiksia neonatorum dibandingkan ibu yang tidak mengalami preeklampsia berat.

Pada penelitian ini tidak terdapat hubungan antara preeklampsia berat dengan asfiksia neonatorum dapat dikarenakan jumlah sampel yang sedikit, selain itu apabila preeklampsia berat baru terjadi saat usia kehamilan mendekati masa persalinan dapat menyebabkan preeklampsia berat yang terjadi tidak berdampak terhadap janinnya.

Tabel 5. Tabulasi silang preeklampsia berat dengan berat bayi lahir rendah

(BBLR)

\begin{tabular}{|c|c|c|c|c|c|c|c|c|c|}
\hline \multicolumn{6}{|c|}{ BBLR } & \multirow{2}{*}{\multicolumn{2}{|c|}{ Total }} & \multirow{3}{*}{$\begin{array}{c}\mathrm{p}- \\
\text { value }\end{array}$} & \multirow{3}{*}{ OR } \\
\hline & & \multicolumn{2}{|c|}{$\mathrm{Ya}$} & \multicolumn{2}{|c|}{ Tidak } & & & & \\
\hline & & $\mathrm{n}$ & $(\%)$ & $\mathrm{n}$ & $(\%)$ & $\mathrm{n}$ & $(\%)$ & & \\
\hline \multirow{2}{*}{$\begin{array}{l}\text { Preeklampsia } \\
\text { Berat }\end{array}$} & $\mathrm{Ya}$ & 14 & 30,4 & 32 & 69,6 & 46 & 100 & \multirow{2}{*}{0,000} & \multirow{2}{*}{19,686} \\
\hline & Tidak & 1 & 2,2 & 45 & 97,8 & 46 & 100 & & \\
\hline
\end{tabular}

Tabel 5. hasil analisis hubungan antara preeklampsia berat dengan berat bayi lahir rendah (BBLR) menunjukan bahwa dari 46 ibu yang mengalami preeklampsia berat terdapat 14 ibu yang mengalami komplikasi janin berupa BBLR (30,4\%). Sementara pada kelompok yang tidak mengalami preeklampsia berat terdapat 1 ibu yang mengalami komplikasi janin berupa BBLR (2,2\%). Hasil analisis chi-square diperoleh nilai $p$ value $=$ 0,000 dan nilai OR sebesar 19,686. Hal ini menunjukkan tidak terdapat hubungan yang bermakna antara preeklampsia berat dengan BBLR, dan ibu dengan preeklampsia berat memiliki risiko 19,686 kali untuk melahirkan bayi dengan BBLR dibandingkan dengan ibu tanpa preeklampsia berat. 
Jurnal Kebidanan Mutiara Mahakam, Vol 7 , No 2, 2019, Hal 74-86

Hasil penelitian ini sejalan dengan penelitian yang dilakukan oleh Mallisa \& Towidjojo (2014), Johan \& Sunarsih (2013), dan Hartati, Surinati, \& Pradnyaningrum (2018) yang menunjukan bahwa ibu dengan preeklampsia berat memiliki risiko 2,58 kali, 5,235 kali, dan 4 kali untuk melahirkan bayi dengan BBLR.

Pada penelitian ini nilai OR yang diperoleh adalah 19,686 lebih tinggi dibandingkan penelitian yang dilakukan oleh Mallisa \& Towidjojo (2014), Johan \& Sunarsih (2013), dan Hartati, Surinati, \& Pradnyaningrum (2018), hal ini mungkin disebabkan karena adanya penyulit preeklampsia berat lain yang dialami oleh ibu, seperti oligohidramnion, riwayat section caesaria, kehamilan multiple, sindroma HELLP, dan solusio plasenta. Selain itu, penyakit penyerta yang sudah dialami oleh ibu sebelumnya juga dapat mempengaruhi kehamilan dan dapat meningkatkan kejadian BBLR, terutama penyakit sistemik yang dapat mempengaruhi peredaran darah dan oksigenasi, seperti stroke, hiperkolestrolemia, dislipidemia, dan hipertensi gestasional.

Ibu dengan paritas 1 dan $\geq 4$ berisiko untuk melahirkan dengan BBLR, pada primipara hal ini disebabkan karena belum adanya pengalaman sebelumnya dalam kehamilan dan persalinan sehingga bisa terjadi status gizi yang kurang yang dapat mempengaruhi berat bayi yang dilahirkan, kunjungan ANC yang kurang serta pengetahuan perawatan selama kehamilan yang belum memadai dan kesiapan mental dalam menerima kehamilan masih kurang. Sedangkan ibu yang pernah melahirkan anak $\geq 4$ lebih sering melahirkan dengan BBLR karena adanya jarigan parut akibat kehamilan dan persalinan terdahulu yang mengakibatkan persediaan darah ke plasenta tidak adekuat sehingga perlekatan plasenta tidak sempurna, plasenta menjadi lebih tipis, mencakup uterus lebih luas dan terganggunya penyaluran nutrisi yang berasal dari ibu ke janin sehingga penyaluran nutrisi dari ibu ke janin menjadi terhambat atau kurang mencukupi kebutuhan janin yang dapat menyebabkan gangguan Pertumbuhan pada janin (Ernawati, 2017).

\section{SIMPULAN}

1. Tidak terdapat hubungan antara preeklampsia berat dengan intra uterine fetal death (IUFD) di RSUD Abdul Wahab Sjahranie Samarinda Tahun 2017-2018

2. Terdapat hubungan antara preeklampsia berat dengan persalinan prematur di RSUD Abdul Wahab Sjahranie Samarinda Tahun 2017-2018

3. Tidak terdapat hubungan antara preeklampsia berat dengan asfiksia neonatorum di RSUD Abdul Wahab Sjahranie Samarinda Tahun 2017-2018 
Jurnal Kebidanan Mutiara Mahakam, Vol 7 , No 2, 2019, Hal 74-86

4. Terdapat hubungan antara preeklampsia berat dengan berat bayi lahir rendah (BBLR) di RSUD Abdul Wahab Sjahranie Samarinda Tahun 2017-2018

\section{DAFTAR PUSTAKA}

Ernawati, W. (2017). Hubungan Faktor Umur Ibu dan Paritas dengan Kejadian Berat Bayi Lahir Rendah di Rumah Sakit Umum PKU Muhammadiyah Bantul Tahun 2016. Skripsi. Yogyakarta.

Gumay, D. O., Wijayanegara, H., \& Zulmansyah. (2015). Hubungan Preeklampsia Berat dengan Hasil Luaran pada Janin (Fetal Outcome) di RSUD Al-Ihsan Kabupaten Bandung. Global Medical and Health Communication, 3, 53-39.

Hartati, N. N., Surinati, I. D., \& Pradnyaningrum, N. N. (2018). Preeklampsia dengan Berat Badan Lahir Rendah (BBLR) pada Ibu Bersalin. Jurnal Gema Keperawatan , 1-9

Heriyanti, O. (2009). Hubungan antara Preeklampsia Berat dengan Asfiksia Perinatal di RSUD Dr Moewardi Surakarta. Skripsi. 39 - 43.

Johan, I., \& Sunarsih. (2013). Hubungan antara Preeklampsia dengan Kejadian BBLR dan Asfiksia Neonatorum di VK IRD RSUD Dr. Soetomo Surabaya. Journal Unair. 7998.

Kirana, R. (2014). Hubungan Preeklampsia dan Perdarahan Antepartum dengan Kejadian Kematian Janin dalam Rahim di Ruang Bersalin RSUD Ulin Banjarmasin. An-nadaa, 48-52

Mallisa, B., \& Towidjojo, V. D. (2014). Hubungan antara Preeklampsia dengan Kejadian Berat Bayi Lahir Rendah (BBLR) di RSUD Undata Palu. Medika Taduloka , 1-7

Mutianingsih, R. (2014). Hubungan Preeklampsia Berat dengan Kelahiran Preterm di Rumah Sakit Umum Provinsi Nusa Tenggara Barat.. Media Bina Ilmiah , 8 .

Ngwenya, S. (2017). Severe preeclampsia and eclampsia incidence,complication, and perinatal outcome at a low resource setting, Mpilo Central Hospital, Bulawayo, Zimbabwe. International Journal of Women's Health , 9, 353 357.

Oktaviani, I. D. (2017). Hubungan Preeklampsia dengan Persalinan Prematur di Rumah Sakit Umum Bahteramas Provinsi Sulawesi Tenggara Tahun 2016. 68-73

Perkumpulan Obstetri dan Ginekologi Indonesia . (2016). Pedoman Nasional Pelayanan Kedokteran: Diagnosis dan Tatalaksana Preeklampsia.

Prawirohardjo, S. (2014). Ilmu Kebidanan Sarwono Prawirohardjo. Jakarta: P.T. Bina Pustaka Sarwono Prawirohardjo. 
Jurnal Kebidanan Mutiara Mahakam, Vol 7 , No 2, 2019, Hal 74-86

Preeclampsia Foundation. (2013). Preeclampsia and Maternal Mortality: A Global Burden. Retrieved Januari 1, 2018, from https://www.preeclampsia.org/advocacy/archive/332-preeclampsiaandmaternal mortality-a-global-burden

PWP, W. S. (2016). Faktor-Faktor yang Berhubungan dengan Kejadian Intra Uterine Fetal Death (IUFD) di RSUD Cibabat Kota Cimahi Tahun 2015. Jurnal Kesehatan Kartika, 26-34.

Rahmawati, D. (2013). Faktor Faktor yang Mempengaruhi Terjadinya Persalinan Preterm di RSUD Dr.Moewardi Surakarta. Skripsi. Surakarta

Saputra, A. N. (2017). Hubungan antara Preeklampsia Berat dan Kelahiran Prematur di Rumah Sakit Dr. Oen Surakarta Periode 2014-2015.Skripsi. 59.

Wibisono, E. H. (2010). Profil Luaran Pasien Preeklampsia Berat-Eklampsia yang Dirawat di RSUD A. W. Sjahranie Samarinda Periode 1 Januari 2008 - 31 Desember 2009. Skripsi. Samarinda.

World Health Organization. (2018). Maternal Mortality. Retrieved November 1, 2018 , fromhttps://www.who.int/newsroom/factsheets/detail/maternalmortality 